\title{
Who, how and what of pathology of soft tissue sarcoma
}

\author{
Salvatore Lorenzo Renne \\ Anatomic Pathology Unit, Humanitas Research Hospital, Humanitas University, Rozzano, MI, Italy \\ Correspondence to: Salvatore Lorenzo Renne. Adjunct Teaching Professor, Anatomic Pathology Unit, Humanitas Research Hospital, Humanitas \\ University, Via Manzoni 56, Rozzano, MI 20089, Italy. Email: salvatore.renne@humanitas.it.
}

Submitted Aug 06, 2018. Accepted for publication Aug 23, 2018.

doi: 10.21037/cco.2018.10.09

View this article at: https://dx.doi.org/10.21037/cco.2018.10.09

\section{Introduction to soft tissue sarcoma (STS) pathology}

STS is a generic term that refers to a heterogeneous group of rare neoplastic diseases. The aim of this review is to discuss the role of pathology in the multidisciplinary management of STS patients. This will be done: (I) illustrating the framework for the current classification; (II) examining the characteristics that allows an expert diagnosis; (III) describing the role of the sarcoma pathologist in patient management; and (IV) discussing some of the most frequent diagnosis and their criticalities.

\section{Classifying STSs}

Soft tissue is generally regarded as the extra-skeletal nonparenchymatous tissue of the body (1), in this location most of sarcomas occurs; they are a heterogeneous group of neoplasms, demonstrating mainly a mesenchymal differentiation, although some of them have neuroectodermal or frank epithelial differentiation (2). The current WHO classification of soft tissue tumors divides benign, malignant and so called "intermediate" neoplasms, defined as locally aggressive or rarely metastasizing neoplasm; but the heart of the classification is the chapter division: the $>80$ histological entities are grouped in twelve chapters that can be reduced to three sections: (I) the differentiated tumors; (II) the tumors of uncertain differentiation; and (III) the unclassified/undifferentiated tumors. Ten chapters of the WHO book are titled with terms indicating "differentiation lines" and are constituted by those tumors that "resemble" a normal mesenchymal cell, therefore demonstrating a morpho-phenotypic differentiation: for example, the chapter of "adipocytic tumor" is dedicated to those tumors that resemble, to a different extent, adipocytes (lipoma, spindle cells lipoma, hibernoma, welldifferentiated liposarcoma (LPS), myxoid LPS, etc.). One chapter is dedicated to specific entities "of uncertain differentiation" that are well-characterized entities that do not readily resemble any normal mesenchymal cells (as the Ewing sarcoma or the synovial sarcoma-a clear misnomer). The last chapter is dedicated to those sarcomas that do not follow in any of the previously listed diagnosis and are therefore called "undifferentiated/unclassified sarcomas" and represent about $25 \%$ all the diagnosis (3). This chapter titles overview shows that the backbone of WHO classification still relies on an "histogenetic" theory, but the concept of histogenesis is probably not applicable in most of the soft tissue tumor, as pointed out by some renowned author (4), in fact tumor with a specific differentiation can occur in places where that tissue is not present (i.e., a LPS in the skeletal muscle). Another relatively simple classification, that can be very useful to keep in mind when talking of sarcomas, is the molecular classification. It is not very new (5), and it has never been formally incorporated in the WHO classification opposed to others WHO blue books $(6,7)$, even if some of the WHO definitions do include molecular alterations (as for synovial sarcoma or myxoid LPS) (3). The molecular classification of STS basically recognizes: (I) tumors with specific translocation (as DDIT3 rearrangement in myxoid LPS); (II) sarcomas with simple genomic profile showing amplification of a few genes (as MDM2 amplification in well/de-differentiated LPS); (III) tumors with activating mutations (as KIT mutation in GIST); (IV) sarcomas with inactivating mutations in a specific pathway (as INI1 deregulation in epithelioid sarcoma); (V) sarcomas with complex genomic profile [as undifferentiated pleomorphic sarcoma (UPS)] $(8-10)$. Most of the STS follows in just three of these 
categories: the translocation, the amplification and the complex genomic profile ones. Of note, this classification has a deep diagnostic implication since translocations and amplifications are readily detectable with relatively simple molecular techniques (9).

The latest WHO classification is mainly based on the concept of differentiation, but it is accepted that certain molecular features are basically diagnostic in the appropriate clinical and pathological context. Given this level of complexity, since the diagnosis is the first step in the patient management, it should be carried out by a sarcoma pathologist.

\section{Experience and expertise in sarcoma pathology}

Several guidelines highlight the need for a second opinion in sarcoma diagnosis, when original diagnosis has been done outside reference centers or networks (11). In a study on three European regions, second opinion led to a change in diagnosis in more than $40 \%$ of cases, with a considerable impact in patient management (12). Another retrospective study in a tertiary center found that diagnosis was changed in $37 \%$ of cases after review, grading in $25 \%$, and margin status, from "negative" to "positive", in 49\% of cases (13). This means that more than a third of the diagnosis made by a general pathologist will change when the case is reviewed by a STS pathologist; it could probably depend both on: (I) pathologist experience-i.e., frequent exposure to soft tissue neoplasm, relationship with sarcoma expert clinicians and feedback from other expert pathologists; and (II) the laboratory expertise, broadly intended as the laboratory skills in sarcoma specimen management-from gross sampling to availability of specific immunohistochemical or molecular assays.

These notions are also supported by the fact that sarcoma patients treated in high volume centers have a better prognosis: a meticulous study of 4,205 patients revealed that sarcoma patient treated in high volume centers had significantly better survival and functional outcomes (14). Several other studies, mainly focused on the role of surgery, confirmed this finding (15-17). Recently also the role of the pathologist have been investigated and, not surprisingly, patient followed in sarcoma centers had pathologic reports of a better quality (18).

A French study also demonstrated that patients who had the initial treatment guided by a multidisciplinary tumor boards (MDTB) [composed at minimum by sarcoma specialized: pathologist(s), radiologist(s), surgeon(s), radiation oncologist(s), medical oncologist(s)] had a significantly better relapse-free survival than those who were treated by the same MDTB after an initial treatment was began outside (19). Moreover, French pathologists have developed an effective network that allows all the participants to monthly review STS cases (about 1,000 cases/year), the same network work as a valid support for second opinion and ancillary testing (20).

An STS pathologist therefore is needed to a good patient management, and as many other medical branches, the job itself relies on a great deal of human factor (21). Patient management and experience in sarcoma pathology could be improved by adherence to guidelines, continuous comparison between peers and discussion with other clinicians involved in the patients care. Similarly, the laboratory expertise can benefit from adherence to external quality assurance programs as well as collaborative efforts in sharing highly specialized technologies.

\section{Histopathological diagnosis in STSs}

According to international guidelines, following an appropriate imaging assessment, diagnostic approach consists preferentially in Tru-cut biopsy gathering multiple cores (with a $14-16 \mathrm{G}$ needle) $(11,22)$. On a retrospective series of 570 patients from a English reference center, Tru-cut biopsy demonstrated a sensitivity of $99.4 \%$, a specificity $98.7 \%$, a positive predictive value $99.4 \%$, and a negative predictive value $98.7 \%$ in differentiating benign from malignant tumors, moreover subtyping was correct in $79.9 \%$ of cases and grading in $84.9 \%$ of cases, compared to final histology (23). These results were comparable to the incisional biopsy, that however was characterized by a higher morbidity than Tru-cut biopsy (23). Of note in all the cases were grading was incorrect $[\mathrm{N}=12(6.7 \%)$ in Tru-cut biopsy and $\mathrm{N}=6(16.2 \%)$ in incisional biopsy] the surgical specimen had an higher grade (23), supporting the common sense notion that needle core biopsy may miss high grade areas and can only give a "minimum grade" (2). When multiple cores are available, it is advisable to divide the cores in multiple paraffin blocks to allow tissue optimization (24).

Together with patient sex and age, several clinical informations can help in the diagnosis of a soft tissue mass: as history of radiation, neurofibromatosis, hypoglycemia in solitary fibrous tumor, or osteomalacia in phosphaturic mesenchymal tumor, speed of growth, pain pattern $(1,2)$; also, a detailed radiological examination is very useful: the 
tumor site, size, depth (in relation to the superficial fascia, i.e., superficial above the fascia, deep in contact with the fascia or intramuscular), relationship with other structures (nerves, vessels, joints) or the presence and pattern of calcifications (2); if feasible, capable pathologist can review radiological imaging as a useful substitute of macroscopic examination. Pathologic diagnosis should be made according to the 2013 World Health Organization (WHO) classification $(3,24,25)$, and should also include, mitotic rate (number of mitosis in the most proliferative area/10 high-power fields (HPF); an HPF defined as $0.1734 \mathrm{~mm}^{2}$ ), percentage of necrosis, and-for primary untreated tumorgrading, the Fédération Nationale des Centres de Lutte Contre le Cancer (FNCLCC) grading system is generally used (24-26).

Once the diagnosis of sarcoma have been made, resectable locoregional disease may or may not undergo neoadjuvant therapy $(11,22)$; in both cases resection specimen will arrive to the grossing room. For the pathologist or the pathologist's assistant, it is useful to examine the specimen together with the surgeon, that can highlight critical margins and re-build the in vivo configuration of the specimen (27). Standard gross description parameters are applied: specimen should be measured in three dimensions, as well as the closest distance of each margin from the edge of the tumor. Tumor relationship with anatomical structures should be recorded, as well as the depth (subcutis, fascial, intramuscular). Size of the tumor, presence of cystic changes, necrosis, as percentage of the total tumor, should be recorded. Blocks are taken to include the margins and generally one per $\mathrm{cm}$ of the maximum diameter of the neoplasm $(24,25)$, alternatively a central slab can be entirely submitted, especially to evaluate pathological response to neoadjuvant therapy (28).

The pathologic report will basically differ for primary tumor, recurrence or relapse, and metastasis [grading in the last two should not be performed since it have not been proven useful, and can be confusing (11)], however the main difference in reporting is case of neoadjuvant therapies: histopathologic report for untreated primary tumor should include the histotype, the size, the mitotic rate, percentage of necrosis, FNCLCC grading, involved viscera or structures, distance from the nearest margins and the margin status. Margin positivity in trunk and extremities is often defined as presence of neoplastic cells $\leq 1 \mathrm{~mm}$ from the inked surface (29); margin status in retroperitoneal sarcoma is also relevant (30-33), however a major limitation when reviewing the literature is that specialist sarcoma centers have different surgical approach and a lack of a common specimen processing, margin sampling, and characterization and definition of organ invasion (27). In contrast, reporting of post-treatment primary tumor should not include the grading, whereas should include assessment of tumor response $(11,28)$. However the value and the modality of tumor response reporting are still controversial: a recent paper from Brigham and Women's Hospital assessing prognostic value of the EORTC-STBSG response score after radiation therapy found no association with tumor viability and outcomes [overall survival (OS) and relapse free survival (RFS)], whereas hyalinization/fibrosis was found a significant independent favorable predictor of RFS and OS (34). The French Sarcoma Group, instead, in a retrospective study of 150 patients that underwent anthracycline-based neo-adjuvant chemotherapy- $90 \%$ of whom underwent also radiation therapy-found that a good pathological response, defined as $<10 \%$ of viable tumor cells on the resection specimen, was associated on uni- and multivariate with a better OS and metastatic progression free survival(mPFS) [multivariate: OS: HR $=0.36(95 \%$ CI: $0.184-0.703), \mathrm{P}=0.0028$; mPFS: $\mathrm{HR}=0.358$ (95\% CI: 0.192-0.668), $\mathrm{P}=0.0012$ ] (35).

Diagnosis of STS is still mostly "histopathological": histotype, size, grading and margin status are the most important pathological information that give the patient prognosis and drive the clinical management $(11,22,36)$. They rely mostly on morphology and immunohistochemistry; molecular pathology can complement histopathology, especially when diagnosis is doubtful, presentation is unusual, and it may have prognostic and/or predictive relevance $(9,11,37)$.

\section{Sarcoma histotyping}

In the searching for papers describing which are the most frequent sarcomas, several epidemiological papers can be encountered, most of them use retrospective database analysis, that cover wide time period $(38,39)$, some are limited to trunk and extremity (40), some to retroperitoneum (41), others span across ages group (42), but all these studies are limited by several major changes recently done in the WHO classification. On the other hand, an epidemiological study lacks an "expert pathologist diagnosis" since often uses the original codification of the general pathologist, therefore data coming from reference 
network could be more accurate $(20,43)$, but may fail to represent the whole picture.

Surprisingly, all these papers agree in the most common STS diagnoses: UPS is the most frequent, followed by LPS, leiomyosarcoma (LMS), myxofibrosarcoma, angiosarcoma, malignant peripheral nerve sheath tumors, synovial sarcomas, and rhabdomyosarcoma.

\section{UPS, a not defined entity}

As already stated, one of the WHO classification chapters is entitled the "undifferentiated/unclassified sarcoma" and is characterized by a surprisingly fluid definition: "a soft tissue sarcoma showing no identifiable line of differentiation when analyzed by presently available technology". Other relevant statements in the definition are: (I) the heterogeneity of this group; (II) the fact that this represents an exclusion diagnosis; (III) other sarcomas may dedifferentiate (i.e., loose that morphophenotypic characteristics that allow a histotype diagnosis) and they do not enter in this category. The only way to subdivide these "undifferentiated/unclassified sarcoma" is on morphologic ground: i.e., by the shape of the cells, when these are pleomorphic (change in shape and size) then the diagnosis of UPS can be made. One might ask if there is a clinical reason for lumping UPS together and to separate them from other sarcomas that shows pleomorphism (morphologic similarities) as well as similar genetic complexity; the answer is probably yes: those studies that tried to assess the effect of histotyping on therapy effect showed that UPS behaved pretty homogeneously at least compared to a better defined entity such LMS: in a recently published multicentric phase III trial in high risk sarcoma, the authors showed that the hazard ratios of disease-free survival estimated with binary logistic models of standard versus histotype-tailored chemotherapy, UPS had an HR $=2.17$ (95\% CI: 0.98-4.80) whereas LMS had a similar $\mathrm{HR}=2.28$ but a pretty larger 95\% CI: 0.27-12.66 (44). Another study that, probably to a minor extent, showed a sort of homogeneity of the UPS group is a phase II trial on pembrolizumab in advanced STS: of the seven patients with clinically meaningful and sustained objective responses four were UPS, and had a much better response than the other group that benefit from pembrolizumab (i.e., dedifferentiated LPS) (45). Sarcoma pathologist is forced to make this "exclusion diagnosis" one time out of four, but this could probably identify a real entity. UPS occurs mostly in older adults and in the soft tissue of the extremity (3).

\section{Synovial sarcoma, not a synovial differentiation}

Between the tumors belonging to the chapter of the "uncertain differentiation", the most common is the synovial sarcoma. It is one of the most durable diagnosis in STS and, although some historical case reports shows questionable examples (46), Stout's epidemiological and clinical observations made on series dating more than 50 years ago fit the one of the current classifications (47), probably because of the characteristic morphologic appearance of the biphasic form; also the synovial derivation have been questioned by a long time (48). This sarcoma occurs mostly in teenagers and young adults (42) and most of the tumors arise in deep soft tissue in joint proximity. Clinically it is often painful and the initial imaging can be misleading and can appear as a benign tumor (49). It is characterized by a variable degree of epithelial differentiation and it is characterized by a specific $\mathrm{t}(\mathrm{X} ; 18)$ chromosome translocation (50), corresponding to the formation of SYT-SSX fusion gene (51). Several morphological subtypes exist: the biphasic, composed by epithelial and spindle cell elements in variable proportions, the monophasic subtype is predominated by spindle cells elements, and the poorly differentiated subtype defined by the presence of hypercellular areas with high grade nuclear features (Figure 1) (52).

\section{LPS, a multitude of neoplasms sharing the lipoblast}

The remaining WHO chapters cover tumors that demonstrate a specific differentiation. Differentiation can be proven by morphology alone or can be supported by immunohistochemical studies. The presence of embryonal type adipocyte, the lipoblast, have been for a long time the key for the diagnosis of LPS (53), which is the second most common reported diagnosis in STS $(20,38,39,41,42)$. The term LPS refers to basically to three different entities: the myxoid LPS characterized by the translocation of DDIT3 gene, the well/de-differentiated LPS characterized by the $M D M 2$ gene amplification and the pleomorphic LPS. The latter is the rarest with a considerable number of cases occurring in the superficial soft tissue and the skin (54). It has neither the translocation of DDIT3 gene nor the $M D M 2$ gene amplification, but is characterized by a complex genomic profile (55). Myxoid LPS is mainly a disease of young adults with a peak of incidence in the fourth decade of life developing preferentially in the lower extremity: particularly the medial thigh and popliteal area $(56,57)$. Histological appearance is a well reported 

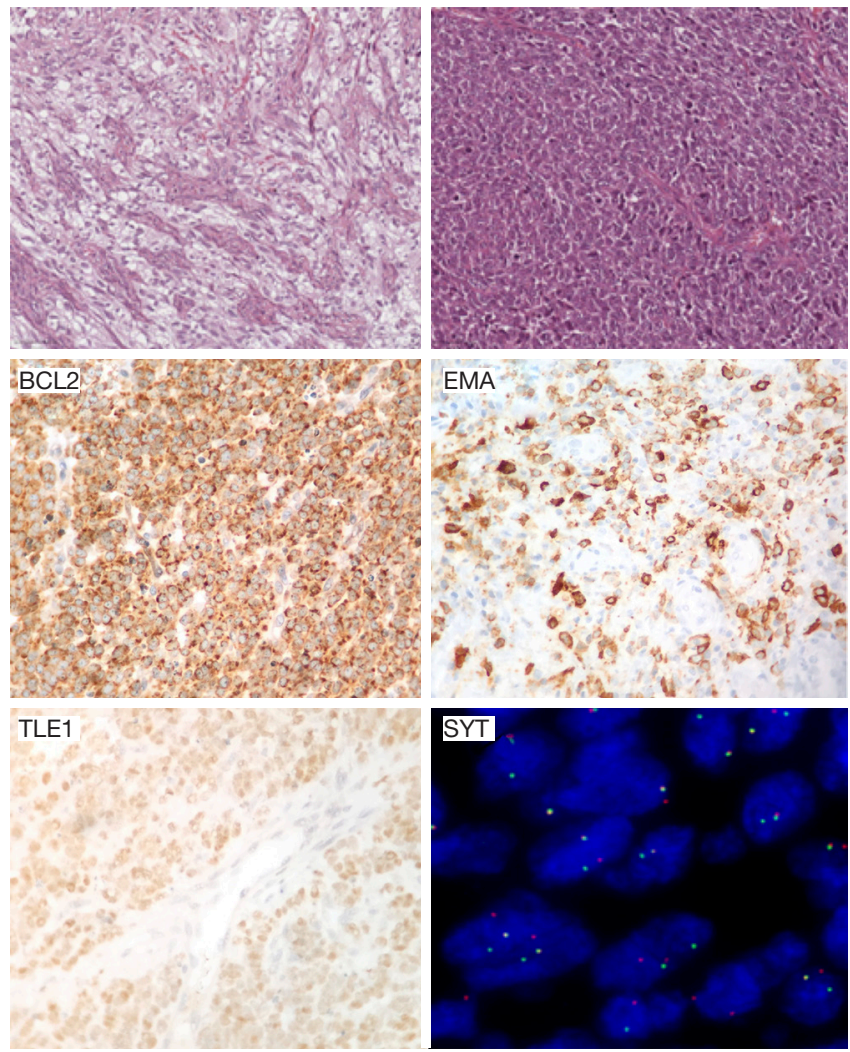

Figure 1 Synovial sarcoma (SS). The upper left image shows a typical biphasic appearance (i.e., spindle cells and epithelial cells), whereas the upper right image shows a monophasic SS (only spindle cells). Lower images show typical immunohistochemical profile demonstrating BCL2 and EMA positivity; TLE1 is a sensitive marker for synovial sarcoma; FISH analysis of SYT with break-apart probes demonstrates the separation of the two signals. HE: images are at $\times 200$ magnification. BCL2, EMA, and TLE1 immunostains are at $\times 400$ magnification. HE, hematoxylin and eosin.

prognosticator for MLS being the round cell variant more aggressive (Figure 2) (56-59).

The majority $(85 \%)$ of the LPS are those characterized by the MDM2 gene amplification, namely: (I) the well differentiated LPS, most often occurring in the deep soft tissue of the extremities, where it is called "atypical lipomatous tumor" (ALT); and (II) the dedifferentiated LPS, which occurs almost exclusively in the retroperitoneal space, where is the most common sarcoma (60). This simplistic division is quite artificial and probably these entity represent a spectrum, in fact several form of the well differentiated LPS exists: they are the lipoma-like, the
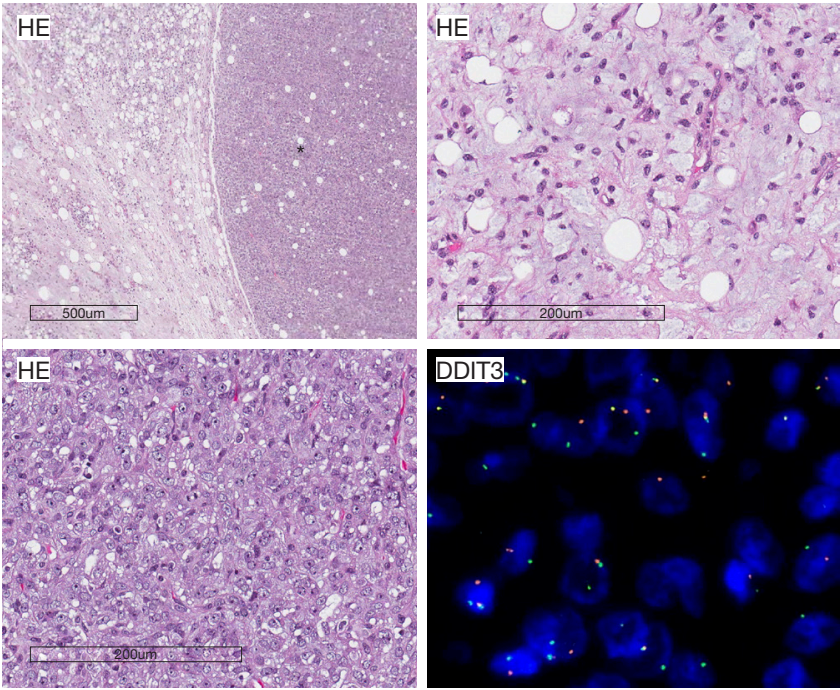

Figure 2 Myxoid liposarcoma (M-LPS). The upper left image shows a solid nodular growth (asterisk) within a proliferation characterized by a myxoid stroma and an adipocytic differentiation; the morphology of the myxoid area is shown in the upper right image: numerous lipoblasts are seen. The morphology of the solidnodular area is shown in the lower left image, where a high grade proliferation of ovoid-round cell is evident, no intervening myxoid stroma is seen. FISH analysis of DDIT3 with break-apart probes demonstrates the separation of the two signals, supporting the diagnosis. Upper left image $\times 40$, other HE: images are at $\times 400$. $\mathrm{HE}$, hematoxylin and eosin.

inflammatory, the sclerosing and the cellular, of note they can all be present within a single neoplasm (3); moreover well differentiated LPS cellular subtype and the low grade dedifferentiated LPS differ basically for the mitotic activity and can be indistinguishable $(3,61)$.

ALT of the extremity is a "locally aggressive" neoplasm that morphologically resembles a lipoma (62) although it can de-differentiate in up to $6 \%$ of cases (63). Retroperitoneal LPS is the commonest sarcoma of the retroperitoneum, often bigger than $25 \mathrm{~cm}$ (60), and should be always ruled out when approaching a undifferentiated sarcoma or a sarcoma showing some extent of myogenic differentiation (i.e., a LMS) $(60,64)$. A major prognosticator of dedifferentiated LPS is the grading of the nonlipogenic component $(60,65,66)$; interestingly once the neoplasm loses the adipose differentiation, it can "gain" other differentiation as muscular differentiation (myogenic), either toward smooth muscle or skeletal muscle differentiation (rhabdomyoblastic), osteogenic or 

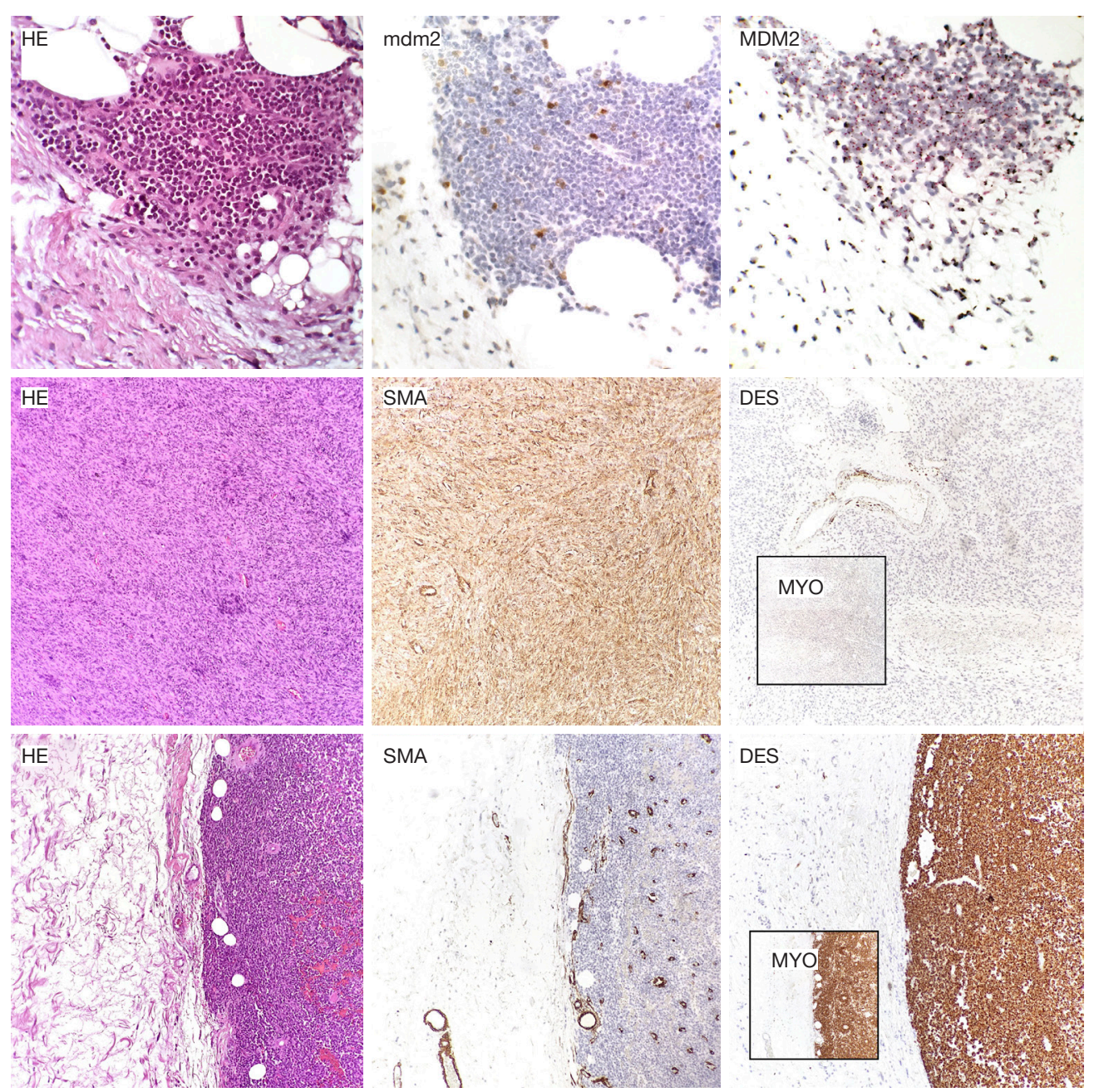

Figure 3 Well differentiated dedifferentiated liposarcoma (WD/DD LPS). Three cases are shown: the first line of images shows a WDLPS inflammatory type, scattered lipoblasts are seen, $\mathrm{mdm} 2$ immunostains show nuclear reactivity and chromogenic in situ hybridization for MDM2 confirms the cluster amplification. The second line shows a DD-LPS with myogenic differentiation: no lipogenic differentiation is seen, SMA is diffusely positive and desmin is focally positive, but myogenin staining is absent; line three: shows a DD-LPS with rhabdomyoblastic differentiation: abrupt transition from lipogenic area is seen, SMA is negative, desmin is diffusely positive, and myogenin positivity confirm the skeletal muscle differentiation. Images from the first case are at $\times 400$ magnification. Images from the other cases are at $\times 100$ magnification. HE, hematoxylin and eosin; MDM2, CISH black signal MDM2, red signal cep12; SMA, $\alpha$-smooth muscle actin; DES, desmin; MYO, myogenin.

chondrogenic differentiation, and also this can impact the prognosis (Figure 3) $(60,67)$.

\section{LMS, a motile definition}

LMS is defined as a malignant neoplasm showing a smooth muscle differentiation, this can be basically demonstrated by morphology and immunohistochemistry (1-3). In contrast to the STSs so far covered, most smooth muscle neoplasms seem to originate from their normal counterpart (4): in fact often LMS have a close anatomic relationship with great vessels (Figure 4) (68-72). Classically LMS have been divided in four clinical forms (4): intra-abdominal/ retroperitoneal (73-75), soft tissue of extremities $(73,76,77)$, vascular $(68-73,78)$ and dermal $(77,79,80)$. Of note, most of the literature favoring a higher prevalence of intrabdomial/ 


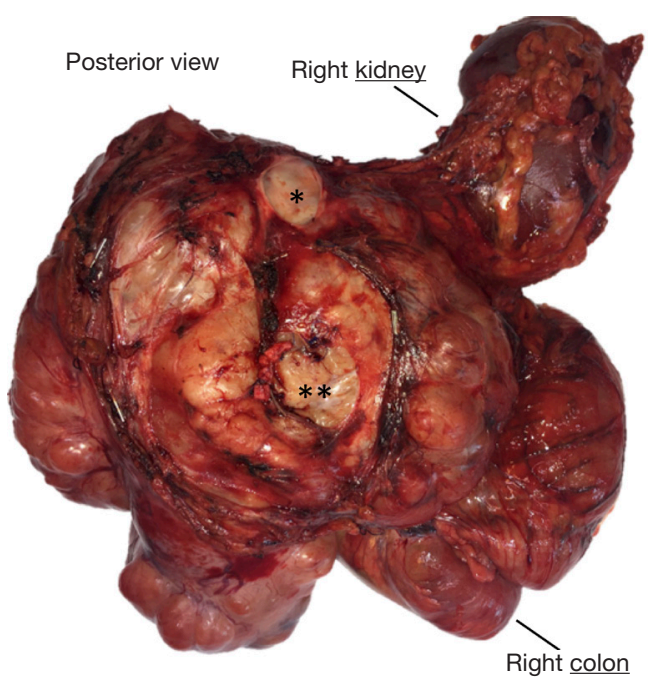

Figure 4 Caval leiomyosarcoma: gross specimen demonstrates the close relationship between the cava and the neoplasm (the cranial margin of the cava is indicated by an asterisk, the caudal margin by two asterisks).

retroperitoneal and extremities LMS over the vascular-LMS precede the widespread use of $i n$ situ hybridization technique to assess the MDM2 amplification status, therefore, knowing that dedifferentiated LPS can have a smooth muscle differentiation (60), these data should be interpreted with some criticism. Concerning the dermal-LMS, some authors consider them to be a non-metastasizing tumor and therefore suggest to use the term "atypical intradermal smooth muscle neoplasm" over sarcoma (80), however this concept is not universally shared (81). In any case when dealing with dermal-LMS the important key feature is that it should be limited to the dermis: in fact a subcutaneous involvement by a dermal centered neoplasm is related to recurrences and metastasis (80-82).

Another important issue regarding LMS is the definition: it has already been underlined how some of the neoplasm called LMS in the past could represent DD-LPS, moreover since no molecular marker to help in the LMS diagnosis is available, to diagnose a LMS pathologist relies clinical information, as the anatomical relationship with vessels or other muscular organs, and pathological ones: the morphology and the immunohistochemistry - the third way would be electron microscopy but nowadays is available only in few centers. Morphology can be very suggestive, LMS are composed, especially lower grade diseases, by fascicles of spindle cells with a brightly eosinophilic cytoplasm and a vesicular, ovoid to cigar-shaped nucleus $(1,3,4)$. To demonstrate the smooth muscle differentiation by immunohistochemistry several markers can be used: (I) desmin, it is expressed both in smooth and skeletal muscle cells, it can also be expressed in several "nonmuscular" neoplasm (83-85); (II) $\alpha$-smooth muscle actin (SMA): it is found in smooth muscle and myofibroblast and in many spindle cell neoplasms both mesenchymal (demonstrating a "myofibroblastic" differentiation) and non-mesenchymal such as sarcomatoid carcinomas and spindle cell melanomas $(86,87)$; (III) high-molecularweight caldesmon (h-caldesmon): it is a marker specific of smooth muscle differentiation although can be positive in gastrointestinal stromal tumors (88); and (IV) calponin: it is expressed by myofibroblasts and smooth muscle cells (88). To diagnose a LMS the tumor should at least focally show the classic morphology and extensive positivity for SMA or calponin, or focal and strong positivity for desmin or h-caldesmon (89-91). LMS can be therefore a challenging diagnosis especially on small specimen, since the muscular differentiation can be only focal.

Many other entities are present in the WHO Classifications, some of them are more frequent in some age group (rhabdomyosarcoma in young patients or congenitalinfantile fibrosarcoma in newborns or toddlers), other are more frequent or almost exclusive of some site (aggressive angiomyxoma in perineal region or myxo-inflammatory fibroblastic sarcoma in distal lower extremity), all of them are diagnosed - with support of clinical information-using the histologic appearance, often together with ancillary tests (immunohistochemical or molecular).

\section{Conclusions}

STSs are rare neoplasms that have been classically divided on the histogenesis, this classification that could have been adequate when diagnoses were performed on morphology alone, seems to have some criticalities given the diagnostic complexity of today.

The diagnosis dictates most of the prognosis (37), and the patient management $(11,22)$, and to be of an high quality a strong cooperation at least between surgeon, radiologist, oncologist and pathologist is needed.

\section{Acknowledgments}

Funding: None. 


\section{Footnote}

Provenance and Peer Review: This article was commissioned by the editorial office of Chinese Clinical Oncology. The article did not undergo external peer review.

Conflicts of Interest: The author has completed the ICMJE uniform disclosure form (available at https://dx.doi. org/10.21037/cco.2018.10.09). The author has no conflicts of interest to declare.

Ethical Statement: The author is accountable for all aspects of the work in ensuring that questions related to the accuracy or integrity of any part of the work are appropriately investigated and resolved.

Open Access Statement: This is an Open Access article distributed in accordance with the Creative Commons Attribution-NonCommercial-NoDerivs 4.0 International License (CC BY-NC-ND 4.0), which permits the noncommercial replication and distribution of the article with the strict proviso that no changes or edits are made and the original work is properly cited (including links to both the formal publication through the relevant DOI and the license). See: https://creativecommons.org/licenses/by-nc-nd/4.0/.

\section{References}

1. Goldblum JR, Weiss SW, Folpe AL. Enzinger and Weiss's Soft Tissue Tumors. Elsevier Health Sciences, 2013.

2. Miettinen M, Fetsch JF, Antonescu CR, et al. Tumors of the Soft Tissues. 4th series, Vol 20. 2015.

3. Fletcher CD, Bridge JA, Hogendoorn P, et al. WHO Classification of Tumours of Soft Tissue and Bone. Fourth Edition. WHO, 2013.

4. Fletcher CD. Diagnostic Histopathology of Tumors: 4th Edition. 2013.

5. Borden EC, Baker LH, Bell RS, et al. Soft tissue sarcomas of adults: state of the translational science. Clin Cancer Res 2003;9:1941-56.

6. Louis D, Ohgaki H, Wiestler O, et al. WHO Classification of Tumours of the Central Nervous System WHO Classification of Tumours, Revised 4th Edition. 2016.

7. Campo E, Harris NL, Pileri SA, et al. WHO Classification of Tumours of Haematopoietic and Lymphoid Tissues. Revised 4th Edition. 2017.

8. Coindre JM. Molecular biology of soft-tissue sarcomas. Bull Cancer 2010;97:1337-45.
9. Bridge JA. The role of cytogenetics and molecular diagnostics in the diagnosis of soft-tissue tumors. Mod Pathol 2014;27 Suppl 1:S80-97.

10. Jain S, Xu R, Prieto VG, et al. Molecular classification of soft tissue sarcomas and its clinical applications. Int J Clin Exp Pathol 2010;3:416-28.

11. Casali PG, Abecassis N, Aro HT, et al. Soft tissue and visceral sarcomas: ESMO-EURACAN Clinical Practice Guidelines for diagnosis, treatment and follow-up. Ann Oncol 2018;29:iv268-iv269.

12. Ray-Coquard I, Montesco MC, Coindre JM, et al. Sarcoma: concordance between initial diagnosis and centralized expert review in a population-based study within three European regions. Ann Oncol 2012;23:2442-9.

13. Randall RL, Bruckner JD, Papenhausen MD, et al. Errors in diagnosis and margin determination of softtissue sarcomas initially treated at non-tertiary centers. Orthopedics 2004;27:209-12.

14. Gutierrez JC, Perez EA, Moffat FL, et al. Should soft tissue sarcomas be treated at high-volume centers? An analysis of 4205 patients. Ann Surg 2007;245:952-8.

15. Bagaria SP, Chang YH, Gray RJ, et al. Improving LongTerm Outcomes for Patients with Extra-Abdominal Soft Tissue Sarcoma Regionalization to High-Volume Centers, Improved Compliance with Guidelines or Both?. Sarcoma 2018;2018:8141056.

16. Venigalla S, Nead KT, Sebro R, et al. Association Between Treatment at High-Volume Facilities and Improved Overall Survival in Soft Tissue Sarcomas. Int J Radiat Oncol Biol Phys 2018;100:1004-15.

17. Maurice MJ, Yih JM, Ammori JB, et al. Predictors of surgical quality for retroperitoneal sarcoma: Volume matters. J Surg Oncol 2017;116:766-74.

18. Hoekstra HJ, Haas RLM, Verhoef C, et al. Adherence to Guidelines for Adult (Non-GIST) Soft Tissue Sarcoma in the Netherlands: A Plea for Dedicated Sarcoma Centers. Ann Surg Oncol 2017;24:3279-88.

19. Blay JY, Soibinet P, Penel N, et al. Improved survival using specialized multidisciplinary board in sarcoma patients. Ann Oncol 2017;28:2852-9.

20. Honoré C, Méeus P, Stoeckle E, et al. Soft tissue sarcoma in France in 2015: Epidemiology, classification and organization of clinical care. J Visc Surg 2015;152:223-30.

21. Pena GP, Andrade-Filho Jde S. How does a pathologist make a diagnosis? Arch Pathol Lab Med 2009;133:124-32.

22. von Mehren M, Randall RL, Benjamin RS, et al. Soft Tissue Sarcoma, Version 2.2018, NCCN Clinical Practice 
Guidelines in Oncology. J Natl Compr Canc Netw 2018;16:536-63.

23. Hoeber I, Spillane AJ, Fisher C, et al. Accuracy of biopsy techniques for limb and limb girdle soft tissue tumors. Ann Surg Oncol 2001;8:80-7.

24. Fisher C. Standards and datasets for reporting cancers Dataset for cancer histopathology reports on soft tissue sarcomas. R Coll Pathol 2017;1-24.

25. Rubin BP, Cooper K, Fletcher CD, et al. Protocol for the examination of specimens from patients with tumors of soft tissue. Arch Pathol Lab Med 2010;134:e31-9.

26. Trojani M, Contesso G, Coindre JM, et al. Soft-tissue sarcomas of adults; study of pathological prognostic variables and definition of a histopathological grading system. Int J Cancer 1984;33:37-42.

27. Strauss DC, Renne SL, Gronchi A. Adjacent, Adherent, Invaded: A Spectrum of Biologic Aggressiveness Rather Than a Rationale for Selecting Organ Resection in Surgery of Primary Retroperitoneal Sarcomas. Ann Surg Oncol 2018;25:13-6.

28. Wardelmann E, Haas RL, Bovée JV, et al. Evaluation of response after neoadjuvant treatment in soft tissue sarcomas; the European Organization for Research and Treatment of Cancer-Soft Tissue and Bone Sarcoma Group (EORTC-STBSG) recommendations for pathological examination and reporting. Eur J Cancer 2016;53:84-95.

29. Gronchi A, Casali PG, Mariani L, et al. Status of surgical margins and prognosis in adult soft tissue sarcomas of the extremities: a series of patients treated at a single institution. J Clin Oncol 2005;23:96-104.

30. Singer S, Antonescu CR, Riedel E, et al. Histologic subtype and margin of resection predict pattern of recurrence and survival for retroperitoneal liposarcoma. Ann Surg 2003;238:358-70; discussion 370-1.

31. Kirane A, Crago AM. The importance of surgical margins in retroperitoneal sarcoma. J Surg Oncol 2016;113:270-6.

32. Fairweather M, Wang J, Jo VY, et al. Surgical Management of Primary Retroperitoneal Sarcomas: Rationale for Selective Organ Resection. Ann Surg Oncol 2018;25:98-106.

33. Renne SL, Tagliabue M, Pasquali S, et al. Prognostic value of microscopic evaluation of organ infiltration and visceral resection margins (VRM) in patients with retroperitoneal sarcomas (RPS). J Clin Oncol 2017;35:11074.

34. Schaefer IM, Hornick JL, Barysauskas CM, et al. Histologic Appearance After Preoperative Radiation Therapy for Soft Tissue Sarcoma: Assessment of the
European Organization for Research and Treatment of Cancer-Soft Tissue and Bone Sarcoma Group Response Score. Int J Radiat Oncol Biol Phys 2017;98:375-83.

35. Cousin S, Crombe A, Stoeckle E, et al. Clinical, radiological and genetic features, associated with the histopathologic response to neoadjuvant chemotherapy (NAC) and outcomes in locally advanced soft tissue sarcoma (STS) patients (pts). J Clin Oncol 2017;35:11014.

36. Callegaro D, Miceli R, Bonvalot S, et al. Development and external validation of two nomograms to predict overall survival and occurrence of distant metastases in adults after surgical resection of localised soft-tissue sarcomas of the extremities: a retrospective analysis. Lancet Oncol 2016;17:671-80.

37. Kandel RA, Yao X, Dickson BC, et al. Molecular analyses in the diagnosis and prediction of prognosis in nonGIST soft tissue sarcomas: A systematic review and metaanalysis. Cancer Treat Rev 2018;66:74-81.

38. Ross JA, Severson RK, Davis S, et al. Trends in the incidence of soft tissue sarcomas in the United States from 1973 through 1987. Cancer 1993;72:486-90.

39. Stiller CA, Trama A, Serraino D, et al. Descriptive epidemiology of sarcomas in Europe: report from the RARECARE project. Eur J Cancer 2013;49:684-95.

40. Trovik C, Bauer HCF, Styring E, et al. The Scandinavian Sarcoma Group Central Register: 6,000 patients after 25 years of monitoring of referral and treatment of extremity and trunk wall soft-tissue sarcoma. Acta Orthop 2017;88:341-7.

41. Nathan H, Raut CP, Thornton K, et al. Predictors of survival after resection of retroperitoneal sarcoma: a population-based analysis and critical appraisal of the AJCC staging system. Ann Surg 2009;250:970-6.

42. Ferrari A, Sultan I, Huang TT, et al. Soft tissue sarcoma across the age spectrum: a population-based study from the Surveillance Epidemiology and End Results database. Pediatr Blood Cancer 2011;57:943-9.

43. Mastrangelo G, Coindre JM, Ducimetière F, et al. Incidence of soft tissue sarcoma and beyond: a populationbased prospective study in 3 European regions. Cancer 2012;118:5339-48.

44. Gronchi A, Ferrari S, Quagliuolo V, et al. Histotypetailored neoadjuvant chemotherapy versus standard chemotherapy in patients with high-risk soft-tissue sarcomas (ISG-STS 1001): an international, open-label, randomised, controlled, phase 3, multicentre trial. Lancet Oncol 2017;18:812-22.

45. Tawbi HA, Burgess M, Bolejack V, et al. Pembrolizumab 
in advanced soft-tissue sarcoma and bone sarcoma (SARC028): a multicentre, two-cohort, single-arm, openlabel, phase 2 trial. Lancet Oncol 2017;18:1493-501.

46. Jones SF, Whitman RC. Primary sarcoma of the lower end of the femur involving the synovial membrane: with a critical review of the literature of synovial sarcoma report of one case with complete pathological and radiographic examination. Ann Surg 1914;60:440-50.

47. Haagensen CD, Stout AP. Synovial Sarcoma. Ann Surg 1944;120:826-42.

48. Stout A, Lattes R. Tumors of the Soft Tissues. National Academies Press, 1967.

49. Bixby SD, Hettmer S, Taylor GA, et al. Synovial sarcoma in children: imaging features and common benign mimics. AJR Am J Roentgenol 2010;195:1026-32.

50. Smith S, Reeves BR, Wong L, et al. A consistent chromosome translocation in synovial sarcoma. Cancer Genet Cytogenet 1987;26:179-80.

51. Clark J, Rocques PJ, Crew AJ, et al. Identification of novel genes, SYT and SSX, involved in the $\mathrm{t}(\mathrm{X} ; 18)(\mathrm{p} 11.2 ; \mathrm{q} 11.2)$ translocation found in human synovial sarcoma. Nat Genet 1994;7:502-8.

52. de Silva MV, McMahon AD, Paterson L, et al. Identification of poorly differentiated synovial sarcoma: a comparison of clinicopathological and cytogenetic features with those of typical synovial sarcoma. Histopathology 2003;43:220-30.

53. Stout AP. Liposarcoma-the Malignant Tumor of Lipoblasts. Ann Surg 1944;119:86-107.

54. Gardner JM, Dandekar M, Thomas D, et al. Cutaneous and subcutaneous pleomorphic liposarcoma: a clinicopathologic study of 29 cases with evaluation of MDM2 gene amplification in 26. Am J Surg Pathol 2012;36:1047-51.

55. Guillou L, Aurias A. Soft tissue sarcomas with complex genomic profiles. Virchows Arch 2010;456:201-17.

56. Fiore M, Grosso F, Lo Vullo S, et al. Myxoid/round cell and pleomorphic liposarcomas: prognostic factors and survival in a series of patients treated at a single institution. Cancer 2007;109:2522-31.

57. Moreau LC, Turcotte R, Ferguson P, et al. Myxoid \round cell liposarcoma (MRCLS) revisited: an analysis of 418 primarily managed cases. Ann Surg Oncol 2012;19:1081-8.

58. Hoffman A, Ghadimi MP, Demicco EG, et al. Localized and metastatic myxoid/round cell liposarcoma: clinical and molecular observations. Cancer 2013;119:1868-77.

59. Antonescu CR, Tschernyavsky SJ, Decuseara R, et al. Prognostic impact of P53 status, TLS-CHOP fusion transcript structure, and histological grade in myxoid liposarcoma: a molecular and clinicopathologic study of 82 cases. Clin Cancer Res 2001;7:3977-87.

60. Gronchi A, Collini P, Miceli R, et al. Myogenic differentiation and histologic grading are major prognostic determinants in retroperitoneal liposarcoma. Am J Surg Pathol 2015;39:383-93.

61. Evans HL. Atypical lipomatous tumor, its variants, and its combined forms: a study of 61 cases, with a minimum follow-up of 10 years. Am J Surg Pathol 2007;31:1-14.

62. Kammerer-Jacquet SF, Thierry S, Cabillic F, et al. Differential diagnosis of atypical lipomatous tumor/ well-differentiated liposarcoma and dedifferentiated liposarcoma: utility of p16 in combination with MDM2 and CDK4 immunohistochemistry. Hum Pathol 2017;59:34-40.

63. Weiss SW, Rao VK. Well-differentiated liposarcoma (atypical lipoma) of deep soft tissue of the extremities, retroperitoneum, and miscellaneous sites. A followup study of 92 cases with analysis of the incidence of "dedifferentiation". Am J Surg Pathol 1992;16:1051-8.

64. Le Guellec S, Chibon F, Ouali M, et al. Are peripheral purely undifferentiated pleomorphic sarcomas with MDM2 amplification dedifferentiated liposarcomas?. Am J Surg Pathol 2014;38:293-304.

65. Keung EZ, Hornick JL, Bertagnolli MM, et al. Predictors of outcomes in patients with primary retroperitoneal dedifferentiated liposarcoma undergoing surgery. J Am Coll Surg 2014;218:206-17.

66. Jour G, Gullet A, Liu M, et al. Prognostic relevance of Fédération Nationale des Centres de Lutte Contre le Cancer grade and MDM2 amplification levels in dedifferentiated liposarcoma: a study of 50 cases. Mod Pathol 2015;28:37-47.

67. Henricks WH, Chu YC, Goldblum JR, et al. Dedifferentiated liposarcoma: a clinicopathological analysis of 155 cases with a proposal for an expanded definition of dedifferentiation. Am J Surg Pathol 1997;21:271-81.

68. Kevorkian J, Cento DP. Leiomyosarcoma of large arteries and veins. Surgery 1973;73:390-400.

69. Varela-Duran J, Oliva H, Rosai J. Vascular leiomyosarcoma: the malignant counterpart of vascular leiomyoma. Cancer 1979;44:1684-91.

70. Berlin O, Stener B, Kindblom LG, et al. Leiomyosarcomas of venous origin in the extremities. A correlated clinical, roentgenologic, and morphologic study with diagnostic and surgical implications. Cancer 1984;54:2147-59.

71. Leu HJ, Makek M. Intramural venous leiomyosarcomas. 
Cancer 1986;57:1395-400.

72. Laskin WB, Fanburg-Smith JC, Burke AP, et al. Leiomyosarcoma of the inferior vena cava: clinicopathologic study of 40 cases. Am J Surg Pathol 2010;34:873-81.

73. Wile AG, Evans HL, Romsdahl MM. Leiomyosarcoma of soft tissue: a clinicopathologic study. Cancer 1981;48:1022-32.

74. Shmookler BM, Lauer DH. Retroperitoneal leiomyosarcoma. A clinicopathologic analysis of 36 cases. Am J Surg Pathol 1983;7:269-80.

75. Hashimoto H, Tsuneyoshi M, Enjoji M. Malignant smooth muscle tumors of the retroperitoneum and mesentery: a clinicopathologic analysis of 44 cases. J Surg Oncol 1985;28:177-86.

76. Farshid G, Pradhan M, Goldblum J, et al. Leiomyosarcoma of somatic soft tissues: a tumor of vascular origin with multivariate analysis of outcome in 42 cases. Am J Surg Pathol 2002;26:14-24.

77. Fields JP, Helwig EB. Leiomyosarcoma of the skin and subcutaneous tissue. Cancer 1981;47:156-69.

78. Gustafson P, Willén H, Baldetorp B, et al. Soft tissue leiomyosarcoma. A population-based epidemiologic and prognostic study of 48 patients, including cellular DNA content. Cancer 1992;70:114-9.

79. Kaddu S, Beham A, Cerroni L, et al. Cutaneous leiomyosarcoma. Am J Surg Pathol 1997;21:979-87.

80. Kraft S, Fletcher CD. Atypical intradermal smooth muscle neoplasms: clinicopathologic analysis of 84 cases and a reappraisal of cutaneous "leiomyosarcoma". Am J Surg Pathol 2011;35:599-607.

81. Winchester DS, Hocker TL, Brewer JD, et al. Leiomyosarcoma of the skin: clinical, histopathologic, and prognostic factors that influence outcomes. J Am Acad Dermatol 2014;71:919-25.

82. Massi D, Franchi A, Alos L, et al. Primary cutaneous

Cite this article as: Renne SL. Who, how and what of pathology of soft tissue sarcoma. Chin Clin Oncol 2021;10(5):53. doi: 10.21037/cco.2018.10.09 leiomyosarcoma: clinicopathological analysis of 36 cases. Histopathology 2010;56:251-62.

83. Bohman SL, Goldblum JR, Rubin BP, et al. Angiomatoid fibrous histiocytoma: an expansion of the clinical and histological spectrum. Pathology 2014;46:199-204.

84. Folpe AL, Weiss SW, Fletcher CD, et al. Tenosynovial giant cell tumors: evidence for a desmin-positive dendritic cell subpopulation. Mod Pathol 1998;11:939-44.

85. Howitt BE, Fletcher CD. Mammary-type Myofibroblastoma: Clinicopathologic Characterization in a Series of 143 Cases. Am J Surg Pathol 2016;40:361-7.

86. Nonaka D, Bishop PW. Sarcoma-like tumor of head and neck skin. Am J Surg Pathol 2014;38:956-65.

87. Longacre TA, Egbert BM, Rouse RV. Desmoplastic and spindle-cell malignant melanoma. An immunohistochemical study. Am J Surg Pathol 1996;20:1489-500.

88. Miettinen MM, Sarlomo-Rikala M, Kovatich AJ, et al. Calponin and h-caldesmon in soft tissue tumors: consistent h-caldesmon immunoreactivity in gastrointestinal stromal tumors indicates traits of smooth muscle differentiation. Mod Pathol 1999;12:756-62.

89. Fletcher CD, Gustafson P, Rydholm A, et al. Clinicopathologic re-evaluation of 100 malignant fibrous histiocytomas: prognostic relevance of subclassification. J Clin Oncol 2001;19:3045-50.

90. Deyrup AT, Haydon RC, Huo D, et al. Myoid differentiation and prognosis in adult pleomorphic sarcomas of the extremity: an analysis of 92 cases. Cancer 2003;98:805-13.

91. Robin YM, Penel N, Pérot G, et al. Transgelin is a novel marker of smooth muscle differentiation that improves diagnostic accuracy of leiomyosarcomas: a comparative immunohistochemical reappraisal of myogenic markers in 900 soft tissue tumors. Mod Pathol 2013;26:502-10. 